\section{Gamma Irradiation as a Quarantine Treatment for Sweet Cherries Against Queensland Fruit Fly}

\author{
Andrew J. Jessup \\ Horticultural Postharvest Laboratory, New South Wales Agriculture \& \\ Fisheries, Gosford, NSW 2250, Australia
}

Additional index words. Prunus aviurn, Cobalt-60, disinfestation, Dacus tryoni

Abstract. The quality of 'Ron's Seedling', 'American Bing', and 'Lambert' sweet cherry drupes was not affected by irradiation doses up to 300 to 1000 gray. Peduncle discoloration increased in 'Ron's Seedling' cherries when irradiated at 600 and 1000 gray. A dose of 75 gray prevented adult eclosion of more than 1300 Queensland fruit fly (Dacus tryoni, Froggatt). Larvae treated at the third instar were the least susceptible to gamma irradiation. The results indicated that gamma irradiation is a feasible quarantine treatment against $D$. tryoni without impairment to the quality of cherries.

Australian cherries can be host to insect pests and are subject to strict quarantine regulations that restrict their movement both interstate and overseas. Japan bans the importation of cherries from Australia due to possible infestation by several pests, including Queensland fruit fly (All-Japan Union of Plant Quarantine Association, 1979). Australian cherries may gain U.S. entry, providing they have been treated with cold storage or a combination of cold storage and methyl bromide fumigation (U.S. Department of Agriculture Animal and Plant Health Inspection Service, 1985). The fruit from most cultivars are tolerant of methyl bromide, although some researchers cite deleterious effects on flavor and external appearance (Claypool and Vines, 1956; Jessup, 1988).

The major drawback of treatments involving cold storage, either alone or in combination with fumigation, is the time required to complete the treatment. This concern is important to trade with Japan, as produce from Australia must be treated before departure from Australia (Higgs, 1987), resulting in a reduction in shelf life, as, on average, shipping time from Australia to most Asian ports is 20 days.

Gamma irradiation can sterilize quarantine pests in just a few hours in many food products with little or no adverse effects on quality (Loaharanu and Urbain, 1982; Dentener et al., 1988). Quarantine security against $D$. tryoni is assured at a dose of 75 gray (Gy) (Rigney and Wills, 1984), while the International Consultative Group on Food Irradiation has stated that a dose of 300 Gy would sterilize any insect infesting fruit (Food and Agricultural Organization/International Atomic Energy Agency, 1986).

Received for publication 13 Feb. 1989. I thank Narelle Quinn and Rod Sloggett of this laboratory and Ashley Gillen of the Australian Nuclear Science and Technology Organization for their assistance in this study. The cost of publishing this paper was defrayed in part by the payment of page charges. Under postal regulations, this paper therefore must be hereby marked advertisement solely to indicate this fact.
This paper reports studies on the effects of irradiation, normal refrigerated storage, plastic film wrapping, and an ethylene absorbant on the appearance and quality of Australian-produced 'Ron's Seedling', 'American Bing', and 'Lambert' cherries, three of the most important cherry cultivars grown in Australia, and on treatment efficacy against eggs and larvae of $D$. tryoni.

All fruit was harvested at Young in southern New South Wales from Dec. 1987 to Feb. 1988. They were cooled overnight to $10 \mathrm{C}$ to. remove field heat then packed in 5kg-capacity cardboard retail display cartons. The fruit was transported to Gosford the next day and sorted into treatment units comprised of 50 fruit each, stored at $10 \mathrm{C}$ overnight, and transported $85 \mathrm{~km}$ by road to the Australian Nuclear Science and Technology Organization (ANSTO) to be irradiated. At ANSTO, the fruit were irradiated in air at $21 \mathrm{C}$ using a $100-\mathrm{kCi}(1 \mathrm{Ci}=37 \mathrm{GBq}) \mathrm{Co}-$ balt-60 source emitting gamma irradiation at a dose rate of $9.25 \mathrm{~Gy} / \mathrm{min}$. Upon return to Gosford, the fruit was stored at $10 \mathrm{C}$ for 10 days or at $1 \mathrm{C}$ for 20 days and then assessed for evidence of damage.

In the first experiment, 'Ron's Seedling' fruit were divided into five replicates of two groups of six plastic containers (50 fruit per of 'American Bing' and 'Lambert' cherries. the mean of five replicates of 50 fruit each.

yScored from 1 (completely green) to 10 (completely brown).

xScored from 1 (completely black) to 5 (completely red). container). The fruit in the first group were covered with commercial plastic wrap (Cryovac v925, 50,000 nm thickness), and in the second, $50 \mathrm{~g}$ of vermiculite impregnated with potassium permanganate was placed in a mesh bag under the wrap. The wrap and potassium permanganate were used to determine if increasing relative humidity or reducing ethylene concentrations would reduce peduncle discoloration (Sharkey and Peggie, 1984). Fruit for each storage treatment were irradiated, in their plastic containers, at $0,75,150,300,600$, or $1000 \mathrm{~Gy}$. For each dose, the five replicates were irradiated separately. After irradiation, fruit were placed for 10 days in a cold room equilibrated to 10C. Ferrous ammonium sulphate (FAS) dosimetry was conducted on one plastic container from each replicate dosed at $300 \mathrm{~Gy}$. The maximum to minimum ratio of dose received was $<2: 1$.

Ten fruit per replicate from each of the six plastic containers per treatment were assessed for the following variables: total soluble solids ( ${ }^{\circ}$ Brix), firmness (determined by the distance each fruit was deformed under a weight of $100 \mathrm{~g}$ for $15 \mathrm{sec}$ ), peduncle discoloration and external damage (scored from 1 to 10 , where $1=0 \%$ to $10 \%$ discoloration or damage and $10=90 \%$ to $100 \%$ discoloration or damage), and average fruit weight. External damage (i.e., skin pitting, browning, or splitting) was also noted. Fruit with a peduncle discoloration score $>5(40 \%$ to $50 \%$ of the peduncle was brown or dried out) were classed as unmarketable.

In the second experiment, five replicates each of 'American Bing' and 'Lambert' cherries were irradiated at $0,75,150$, or 300 Gy and then stored at $1 \mathrm{C}$ for 20 days to study the effects of a combination irradiation and cold storage treatment. Ten fruit per replicate were assessed for degree of peduncle abscission using a clamping device that held the fruit while the peduncle was removed. The force required to remove the peduncle was measured in grams. External damage and degree of skin browning were scored on 20 fruit per replicate using the same method as in the first experiment. Skin color was also assessed for these fruit and scored from $1=$ completely black to $5=$ completely red. Data

Table 1. Effects of gamma irradiation and subsequent storage at $1 \mathrm{C}$ for 20 days on quality attributes

\begin{tabular}{|c|c|c|c|c|}
\hline \multirow[b]{2}{*}{ Attribute } & \multicolumn{4}{|c|}{ Dose $(G y)^{z}$} \\
\hline & 0 & 75 & 150 & 300 \\
\hline \multicolumn{5}{|c|}{ American Bing } \\
\hline Peduncle discolorationy & $2.05 \mathrm{~b}$ & $2.28 \mathrm{a}$ & $2.27 \mathrm{a}$ & $2.37 \mathrm{a}$ \\
\hline Skin color ${ }^{x}$ & $1.83 \mathrm{a}$ & $1.84 \mathrm{a}$ & $1.72 \mathrm{~b}$ & $1.76 \mathrm{~b}$ \\
\hline External damage & 1.52 & 1.39 & 1.57 & 1.47 \\
\hline \multirow{2}{*}{\multicolumn{5}{|c|}{ Force to temove peduncie (g) }} \\
\hline & & & & \\
\hline Peduncle discoloration ${ }^{y}$ & $2.34 \mathrm{a}$ & $2.17 \mathrm{~b}$ & $2.21 \mathrm{ab}$ & $2.12 \mathrm{~b}$ \\
\hline Skin color ${ }^{x}$ & $1.77 \mathrm{a}$ & $1.63 \mathrm{~b}$ & $1.68 \mathrm{~b}$ & $1.67 \mathrm{~b}$ \\
\hline External damage & 1.31 & 1.27 & 1.49 & 1.40 \\
\hline Force to remove peduncle (g) & $7.1 \mathrm{a}$ & $5.7 \mathrm{~b}$ & $6.6 \mathrm{ab}$ & $6.7 \mathrm{ab}$ \\
\hline
\end{tabular}

${ }^{2}$ Mean separation in each row by Duncan-Waller Bayesian $k$ ratio test $(k=100)$. Each figure represents 
Table 2. Pupal formation from immature stages of $D$. tryoni in 'Ron's Seedling' cherries after gamma irradiation.

\begin{tabular}{lccc}
\hline \hline & \multicolumn{3}{c}{ Dose (Gy) $)^{2, y}$} \\
\cline { 2 - 4 } Stage & 0 & 75 & 300 \\
\hline Egg & 460 & $0(100)$ & $0(100)$ \\
First instar & 389 & $0(100)$ & $1.3(97.7)$ \\
Second instar & 577 & $430(25.5)$ & $419(27.7)$ \\
Third instar & 505 & $458(9.3)$ & $495(2.1)$ \\
\hline
\end{tabular}

${ }^{2}$ Each datum represents the mean number of pupae formed from five replicates of 160 fruit each. rNumbers in parentheses represent percent mortality and are based on pupal formation from nonirradiated ( $0 \mathrm{~Gy})$ 'Ron's Seedling' cherries infested with immature lifestages of $D$. tryoni.

Table 3. Survival of third instar D. tryoni to adult eclosion in 'Ron's Seedling' cherries after gamma irradiation.

\begin{tabular}{cccc}
\hline \hline Dose $($ Gy) & $\begin{array}{c}\text { Pupae formed } \\
\text { (no.) }\end{array}$ & $\begin{array}{c}\text { Emergent adults } \\
\text { (no.) }\end{array}$ & Emergence (\%) \\
\hline 0 & $1450^{y}$ & 1389 & 95.8 \\
75 & 1080 & 0 & 0 \\
100 & 1238 & 0 & 0 \\
\hline
\end{tabular}

zTotal number of pupae from five replicates of 100 fruit each.

YTotal number of emergent adults from five replicates of 100 fruit each.

from both experiments were tested by analysis of variance (Alvey et al., 1983). Where differences between treatment means were significant $(P<0.05), \mathrm{K}$-LSD values were calculated at $\mathrm{k}=100$ using the DuncanWaller Bayesian k ratio test (Chew, 1977).

To test the efficacy of irradiation against D. tryoni, five replicates each of 160 'Ron's Seedling' cherries were infested in the laboratory with $D$. tryoni eggs (Rigney and Wild, 1975 ) by placing the fruit on mesh cages housing 3- to 5-week-old adult flies and allowing oviposition through the mesh. Infested fruit were stored at $26 \mathrm{C}$ and $70 \% \mathrm{RH}$, the optimum conditions for the development of $D$. tryoni, until larvae had attained first, second, and third instars. Infested fruit were then irradiated when insects were at the egg stage and the three larval stages, separately. Doses received were 0 (nonirradiated control), 75, and $100 \mathrm{~Gy}$. Dosage was confirmed using FAS dosimeters on the 75-Gy fruit. After irradiation, the infested fruit were stored at 26C over dry sand in which surviving larvae pupated. Pupae were collected, and the least susceptible D. tryoni stage was determined based on the relative number of pupae formed.

In a follow-up experiment, five replicates each of 100 fruit were infested with $D$. tryoni eggs, irradiated at 0,75 , or $100 \mathrm{~Gy}$ once the larvae had developed to the most tolerant stage, and stored as above. Surviving pupae were collected and stored at $26 \mathrm{C}$ and the number of emergent adult flies was recorded. The efficacy of the treatment was based on successful adult eclosion.

Following the irradiation of 'Ron's Seedling' cherries and subsequent storage at 10C for 10 days, there were no significant irradiation effects on total soluble solids (10.9 to $12.1{ }^{\circ} \mathrm{Brix}$ ), firmness (deformation 0.49 to $0.58 \mathrm{~mm}$ ), external damage (score 6.3 to 7.0 ), or fruit weight (5.7 to $5.9 \mathrm{~g}$ ). Peduncle discoloration was linearly correlated with dose $(\mathrm{y}=0.0017 \mathrm{x}+2, r=0.96)$, based on mean values from five replicates of 60 fruit each. As peduncle discoloration in fruit ir- radiated at 600 and $1000 \mathrm{~Gy}$, with average scores of 3.40 and 3.58, respectively, did not attain a score $>5$, the fruit were classified as commercially acceptable. The addition of potassium permanganate did not reduce the extent of external damage or peduncle abscission.

In the second experiment, there were no significant differences in firmness, the force required to remove the peduncle from the drupe, or external damage when 'American Bing' or 'Lambert' cherries were irradiated at doses up to $300 \mathrm{~Gy}$ and then stored at $1 \mathrm{C}$ for 20 days (Table 1). There were significant differences in color, with irradiated fruit tending to remain redder than the controls. Cultivar response varied with respect to peduncle discoloration, where irradiation adversely affected 'American Bing' cherries, but not 'Lambert' cherries. The discoloration, however, would not be expected to render the 'Bing' fruit unmarketable.

Other researchers have found significant though small, deterioration in firmness, flavor, and appearance in 'Bing' cherries dosed at 600 to 800 Gy (Johnson et al., 1965); adverse texture effects have also been reported when fruit were irradiated (U.S. Atomic Energy Commission, 1965). In another study, irradiation at 2000 to $4000 \mathrm{~Gy}$ in combination with refrigeration enhanced the storage life of 'American Bing' cherries (Salunkhe and Desai, 1983).

Second and third instar larvae of D. tiyoni were more tolerant than eggs or first instar larvae (Table 2) in terms of the number of pupae formed after fruit were irradiated. No insect survived to adult eclosion when third instar larvae of $D$. tryoni were irradiated at 75 or 100 Gy (Table 3).

The results indicate that a dose of $75 \mathrm{~Gy}$ could provide quarantine security against eggs and larvae of $D$. tryoni in cherries by breaking the life cycle of the fruit fly at adult eclosion. This treatment will not affect cherry fruit quality, but efficacy trials must be conducted to confirm quarantine security at the probit 9 level (99.99683\% mortality), which is the level required by the U.S. Animal and Plant Health Inspection Service for the importation of fresh fruit and vegetables into the United States (Baker, 1939). Irradiation even at a dose as low as 75 Gy delayed the normal skin coloration of the red-skinned cherries 'Lambert' and 'American Bing'. Irradiation may, therefore, have some benefit in prolonging the shelf life of some cherry cultivars. Further research is required to test this hypothesis.

\section{Literature Cited}

All-Japan Union of Plant Quarantine Associations. 1979. Plant protection law and enforcement regulations, p. 24-109. In: Law, regulations and ordinances relevant to plant protection. Ministry of Agriculture, Forestry, and Fisheries, Tokyo.

Alvey, N.G., C.F. Banfield, R.I. Baxter, J.C. Gower, W.J. Krzanowski, P.W. Lane, and P.W. Leech. 1983. GENSTAT-A general statistical package. Lawes Agricultural Trust, Rothamstead Experimental Station, United Kingdom.

Baker, A.C. 1939. The basis for treatment of products where fruit flies are involved as a condition for their entry into the United States. USDA Circ. 551:1-7.

Chew, V. 1977. Comparisons among treatment means in an analysis of variance. USDA/ARS/ H/S. U.S. Government Printing Office, Washington, D.C.

Claypool. L.L. and H.M. Vines. 1956. Commodity tolerance studies of deciduous fruits to moist heat and fumigants. Hilgardia 24:297-355.

Dentener, P.R., D.B. Birtles, B.C. Waddell, and P.S. Stevens. 1988. Irradiation of Epiphyas postvittana (Walker), lightbrown apple moth. Dept. Scientific Ind. Res., Entomol. Div., Auckland, New Zealand.

Food and Agricultural Organization/International Atomic Energy Agency. 1986. Excerpt of the task force meeting on irradiation as a quarantine treatment. Chiang Mai, Thailand, 17-21 Feb. 1986. Food Irradiation Nwsl. 10:5-10. Vienna, Austria.

Higgs, G.M. 1987. Summary of overseas countries requirements for entry of fresh fruit and vegetables. New South Wales Agriculture \& Fisheries, Export and Imports Branch, Sydney, Australia.

Jessup, A.J. 1988. Response of 'Lambert' and 'Ron's Seedling' sweet cherries to fumigation with methyl bromide plus cold storage. Austral. J. Expt. Agr. 28:431-434.

Johnson, C.F., C. Boyd, and E.C. Maxie. 1965. Radiation technology in conjunction with postharvest procedures as a means of extending the shelf life of fruits and vegetables. Annual Report AT (11-1)-34, 48-51. Div. of Isotopes Dev., U.S. Atomic Energy Comm., Washington, D.C

Loaharanu, P. and W.M. Urbain. 1982. Certain utilization aspects of food irradiation, p. 65-78. In: E.S. Josephson and M.S. Peterson (eds.) Preservation of food by ionizing radiation. vol. 1. CRC Press, Boca Raton, Fla.

Rigney, C.J. and B.L. Wild. 1975. Dacus tryoni: Ethylene dibromide treatment of oranges. J. Econ. Entomol. 68:653-654.

Rigney, C.J. and P.M. Wills. 1984. Efficacy of gamma irradiation as a quarantine treatment against Queensland fruit fly, p. 116-120. In: J.H. Moy (ed.). Proc. Intl. Conf. on Radiation Disinfestation of Food and Agricultural Products. Univ. of Hawaii at Manoa, Hawaii.

Salunkhe, D.K. and B.B. Desai. 1983. Postharvest biotechnology of fruits. CRC Press, Bota Raton, Fla. 1:47-48. 
Sharkey, P.J. and I.D. Peggie. 1984. Effects of high-humidity storage on quality, decay and storage life of cherry, lemon and peach fruits. Scientia Hort. 23:181-190.

U.S. Atomic Energy Commission. 1965. Sum- mary of fruit and vegetable roundtable discussion. p. 138-141. In: Radiation pasteurization of foods, fifth annual contractors meeting, October 20-21. Div. Tech. Info., Washington, D.C. U.S. Department of Agriculture Animal and Plant
Health Inspection Service. 1985. Plant protection and quarantine treatment manual. T101 (a and c), T107 and TI08 (a and b). USDA, Washington, D.C. 